\title{
Stagnation in Identity-based Community: The Experience of Buton Youth Community
}

\author{
Dondick Wicaksono Wiroto $1 \bowtie$ \\ ${ }^{1}$ Universitas Negeri Gorontalo, Indonesia
}

DOI: http://dx.doi.org/10.15294/komunitas.v8i2.5032

Received : 10 February 2016; Accepted: 8 August 2016; Published: 30 September 2016

\begin{abstract}
Youth college student communites in Gorontalo are interesting to study because almost all of these communities are formed by the reason of ethnic and regional origin. This study uses a youth community, namely HIPPMIB (Himpunan Pemuda Pelajar Mahasiswa Indonesia Buton /Youth Association of Indonesian Students Buton) as the subject under study. At this time, HIPPMIB in Gorontalo is experiencing stagnation, as fewer members attending community events. There are several factors that cause the community to stagnate, such as the community does not function well and the alienation of the members from the community. Data collected through focus group discussions (FGD) illuminate that the youth community Buton in Gorontalo city needs to increase its understanding of the community, reflect its experience and reorganized the community so that cohesion remains intact and symptoms of alienation can be addressed.
\end{abstract}

Keywords: community; stagnancy; identity; youth

\section{INTRODUCTION}

Gorontalo is a destination city for majority of youth who live in Sulawesi to study in a university. They come from parts of northern, central, and south eastern of Sulawesi, north Maluku, and Papua, making Gorontalo a multiethnic city. Some of the graduates of the university in Gorontalo decide to look for a job there, and some choose to return to their hometown. Nevertheless, the alumni and students from the same region and ethnic background maintain their connection, in that way they can share learning and living experiences in Gorontalo to newcomers and juniors as well as information related to job opportunity, get additional skills or money, and other specific interests between them.

These young people from the same region and ethnic background join together in a community built by founder seniors. It has since become a very important coordinating institution so that the kinship relations and created cooperation can last. Despite the strong relationship between the members, city life can disrupt the harmony as explained by Louis Wirth (1930); a loss of kinship and participation in the neighborhood as the source of solidarity and control in society is because city and its unfamiliar features could result an anonym between the people (Lin \& Mele 2005, p. 35). It will alter the social ties of members in community to condition of alienation, a condition when a person has lost the feeling and meaning as a part of community and believes that the other members will disregard his/her existence there. This study is about youth organization, its activity and its contemporary challenge. Studies about youth rarely discusses their involvement in community organizations (Checkoway and Gutierrez 2006; Pittman, Martin and Williams 2007; Wheeler and Edlebeck 2006; Wang 2006; Nygreen, Kwon and Sanchez 2006).
Corresponding author:

Address: Jurusan Sosiologi, Fakultas Ilmu Sosial, J1. Cokroaminoto no. 227 Kota Gorontalo

Email : dondick.wicaksono@gmail.com

Phone : 081382356658
(C) 2016 Semarang State University. All rights reserved p-ISSN 2086 - 5465 | e-ISSN 2460-7320 
Nowadays, young people who live in the city are at the intersection between the end of a social model of youth produced by industrial society (Arcidiacono et al. 2007; Nygreen, Ah Kwon and Sanchez 2006). Moreover, a new social experience of youth is even more shaped by the imperatives of mobilization than by roles, and by the imperatives of communication rather than by function (Evans and Prilleltensky 2007; Lerner 2005). They are facing an unstable role and status when they were understood in the context of generation and class, because both of these contexts had been experiencing deinstitutionalization and desocialisation (McDonald 1999, p.4-5). The youth should function as people who continue the older generation and replace their roles in the society. Nowadays, senior and young people are being challenged with a number of developments in information and technology, and because of that any attempts to categorize them in age groups based on their ability to use technological information will be very difficult (Sexton and Turner 2010; Wang 2006). In the end, the socialization of norms in later generation and their roles in the society gradually disappear, because the generation itself is evolving and mobilized into a form of society that does not recognize any boundaries: the era of digital societies. This led to the changing perception in class category of youth. A few years ago, the youth are classified based on their social status, now they are divided by their ability to communicate in public, their creativity and capacity for being independent, and their contribution to society (Watts and Flanagan 2007; Wheeler and Edlebeck 2006).

Alienation, deinstitutionalization, and desocialisation may cause them to distance themselves from their relationship with the community, despite their relation and connection to the same background (ethnic, tradition, history and hometown). These three matters may generate a disorder in community's cohesiveness that has been well-maintained up until today. Alienation to community has a number of variations: adolescent peer group, poverty and deviance, fun- damentalism, and virtual communities (Internet use) (Christensen \& Levinson 2003, p.31-34. This research is directed to answer a couple of problems: how do the members of Buton youth community (HIPPMIB) understand the function of community and how well is the preparation of HIPPMIB in maintaining the cohesion between the members in order to prevent the alienation at hand to extend.

\section{RESEARCH METHODS}

This research was conducted using qualitative approach and the data were collected using focus group discussion (FGD) method. FGD is a model of discussion that is systematically carried out to focus on a certain theme or particular issue (Budiman, Munawar, and Djohar 2013, p.37). It was participated by 22 participants of HIPPMIB (Association of Buton-Indonesia Youth and University Students) and one presenter (researcher). The participated members were divided into two groups based on gender. The purpose of this grouping was to simplify the observation of different reactions, behaviors and ideas resulted from both groups particularly at a certain topic of discussion that the answers need to be collected collectively.

Some major topics discussed in the FGD were: a) member's feeling about the implementation of HIPPMIB's mission and vision; b) identification about deviant behavior and the distancing relationship in the community; c) the community's experience of conflict and its settlement; d) identification about the integration between the function of community and Internet media to improve achievement and creativity of the members; e) the community's obstacles in maintaining the cohesiveness between the members. All the data resulted from FGD were analyzed to produce sociological discussion and proposition that can be used to empower the community and its members.

\section{RESULT AND DISCUSSION}

This research has two main results, first is undeveloped function of Buton youth community and second is identification of the alienation in the community (emphasizing 
on the factor of Internet use). The discussion towards both results was performed by criticizing the limits in community's point of view about the function of community and in its efforts to fix the distancing relationship and maintain the cohesiveness between members. Furthermore, the discussion has two focuses, first is on the developing concept of community, and the second is on the changing of sociological approaches for Buton community.

\section{Undeveloped Function of Buton Youth Community}

The members of HIPPMIB appreciate many changes occurred in the realization of community's vision which is based on the spirit of "Bolimo Karo Somanamo Lipu" or "prioritizing public interests rather than private ones" with the purpose to work together in developing their hometown. However, they frequently abandon many traditionally important agendas despite acknowledging that the purpose is to strengthen the solidarity between individual in the community. Members who actively maintain the solidarity by constantly telling others the importance of routine occasions see many members who were assisted by the community when they first came to Gorontalo no longer continue their relationship with their friends from the same hometown.

All members have not realized the maximum function of the community. It is not surprisingly that many of them do not think about the various benefits from being in one. HIPPMIB and do not have any initiatives to make communication among members well persisted and stronger. One of the examples is about fund supporting for friends who are unable to pay for medical treatment expenses. Up until now, they usually collect money from members while knowing that the donation collected is often insufficient. The fact that many members are students working in sectors which pay them mediocre income only enough to make ends meet for them and their family becomes the main obstacle. This explains the situation where members have limited ability to help each other during illness.
Some other things that identifies that HIPPMIB still does not perform well to fulfill the needs of its members are;it is still unable to become a medium to student members in obtaining reference books due to the lack supply in Gorontalo; the secretariat has not yet been able to provide permanent headquarter owing to the increase of price in property renting, this problem often makes members have to travel far distance to reach it; it has not fulfilled its function as an agent for members who are looking for job information in Gorontalo.

In accordance with the conflicts that may occur in the community, every member is aware that the spirit of Bolimo Karo Somanamo Lipu can be understood as whenever a problem arise, therefore conflicts between members have to be settled immediately and cannot be brought to their hometown. Moreover, they should not affect the harmonization of relationship between families back home. If the community does not quickly resolve the conflict and reconcile with disputed members, then it is clear that it can possibly cause disunity in the relationship among families.Therefore, they are always very perceptive and quick in resolving conflicts to avoid them become unsolved which can lead to major problems when other conflicts arise and involve the same members from previous ones.

Researcher concluded above indication during discussion of a topic about the community's experience of conflicts and their settlements. As the participants of FGD were divided in two groups based on gender, researcher asked both groups to choose whether this topic was going to be discussed or not, and if they chose to discuss it then the next step is to consider a case of a conflict they want to share and then discuss it. When each group's representations explained something to the rest of the members, the male group was more serious and tensed compared to the female one. While the decision making was still in progress, the representations from female group came forward and mentioned to the researcher: "we have no problem with this topic, and it would be better if we agree with 
the men." After that, the representations of the women group join the discussion in the men group. Finally the male group decided to continue to discuss this topic and chose only one case which was considered insensitive. This process described the fact that the members of HIPPMIB are very discreet in their social relationship. Moreover, the women in the community give high respect for the men, in the era where norms that regulate relationship between men and women are becoming more and more flexible, causing the women to have an equal position in terms of giving opinion. The participants in the female group could convey their thoughts without having to wait the opinions from the male group.

The conflict they agreed to discuss was trivial, about a borrowed book. Although the chosen case seemed unimportant, but almost everybody had an experience with it, with varieties of solving efforts. It occurred between $A$ and $B$, two members who happened to be close friends and roommates. A asked about a book borrowed by B, but B no longer had it. Somehow, A thought that B was responsible for giving it back. This situation has made B felt annoyed and said improper words to $\mathrm{A}$, and after that $\mathrm{B}$ chose to move out from the dorm. This misunderstanding had worsened the already bad relationship between the two members, until both of them pried wider problems that related to their families. At that time, the situation between the former roommates was really bad, said the participants. Finally, on the third day of the conflict, other members of the community took an action to reconcile the conflict. A quick mediation was made and the two disputed members realized their mistakes and the risk if they continued to prolong the conflict.

The situation and condition explained above describe that the function of HIPPMIB is undeveloped, because the members from Buton who do not know Gorontalo well enough considered the community as a transit, a temporary place to stay, a place to ease their homesick, and a place where they can count on other members for financial support whenever they fall into illness or need money for basic necessity.

\section{Identification of the Alienation in Bu- ton Youth Community (Emphasizing on the Factor of Internet Using)}

The scope of alienation which the researcher wanted to explain was the deviant behavior and the Internet using in the community. Nevertheless, researcher found difficulty to attain information about the behavior using only FGD as the media to collect data. Researcher decided not to continue to discuss the subtopic after what had happened in discussing about the community's experience in conflict and its resolution. Hence, the discussion was only focusing on observing how far is the awareness of the community towards the penetration of the Internet in social life that may drive its members to use it for positive and negative purposes.

There were two major concerns form male and female groups about the negative intentions from Internet using, first was for pornography and the second was the hegemony of the Internet's negative functions. The pornography contents in the Internet can be the factor of alienation because people who access it have the tendency to isolate themselves alone in a room or with others with similar interest. According to the participants, this self-alienation probably occurred as a form of punishment. Pornographic materials accessed from notebooks, laptops, or smartphone which can be traced from the browser history often cause relationship problems when found by other people, in particular between the men and the women. This is mostly because the women pay high respect to the men, and if it was a man who was caught accessing pornography, it will cause him to lose respect from all the women. On the contrary, if it was a woman, it will cause her the humiliation from the majority members in the community.

The participants of FGD were aware that the Internet can be very hegemonic, particularly because of its negative functions. Most of the members in the community felt that social media consume too much of their time while they are accessing the Internet. It would divert them from their 
initial objectives and mostly because of the excessive interaction with its application. Interactions in the social media are over practiced and addictive because it feeds users' curiosity of other people's life; their looks, facial expressions, clothes, body shape, activities, and personal information. Often times, the excessive Internet use affects one's behavior when being in the community such as carried away to gossiping other's physical and behavior in social media, whether if it is of public figures or people they know. If this practice happened between members in the community then it may detract the trust which has developed between them.

On the other hand, members of HIPPMIB also believe that Internet has a positive function that may help them maintaining integration in the community. The social media applications such as Blackberry Messenger (BBM), WhatsApp, Facebook, Twitter, and LINE have been used to successfully promote Makassar traditional food called Pisang Ijo that was made by some community members and customers take advantage of mentioned applications to order the food. Unfortunately, the promotion and service through social media were forced to stop several times, because they did not allocate the sales revenue to maintain the promotion, e.g. to continue subscribe the Internet, so they were unable to continue the promotion and responded orders from customers.

Additionally, the community has made a useful Internet blog to inform public about their activities and also to promote the beauty of Buton island. This blog contains information about HIPPMIB's experience in Gorontalo for the people in their hometown who have never come there. It is used to share morale to their junior in Buton who are about to take national graduation examination (ujian nasional) by uploading motivational messages that contain words, pictures and photograph of the seniors in Gorontalo. They also used YouTube to promote the beauty of Buton Island and its unique animals, plants and fruits. All these positive experience of Internet use demonstrate that HIPPMIB pays serious attention in order to procure some ways to maintain the cohesi- veness between the members.

\section{Concept of Community is Developing}

Community is a group of humans which forms interrelationship based on identity of place, tradition, culture, history, role and status. Human beings as complex creatures need interactions with others to fulfill their physical needs such as foods and housing, and psychological needs, such as to feel safe. Community gives a feeling that other people cares with something happen to us and that we can depend on the people around us (Henslin 2006, p. 206). However, community encounters the dynamic and changing in the relation of the members, as already happened to the Buton youth community (HIPPMIB). Many of its members only took advantage of the community when they first arrived and lived in Gorontalo and after a while they stopped and did not continue the effort to build a strong relationship with other members.

Individual relations surely change, but their dynamics have to be learned because the case can be different in every community. The spirit and motto of HIPPMIB "Bolimo Karo Somanamo Lipu" or "prioritizing public interests rather than private ones" is considered as not very successful to motivate its members to care for each other. This is probably because the community is run by few committees and members only. It is facing a stagnancy: the community, with its limitations, always tries to liven up and keep the social networking of the senior members with a job and juniors who still study in university by holding gathering events such as pengajian (recitation and study of the holy Koran) and other religious events and feasts that interspersed with advice from seniors. the preparations and implementations of new students orientation, fund raising for ailing members, and also searching for a rented property for community secretariat, yet in the same time it is abandoned by the members. At one point, a member said to the researcher, "I have no idea about the future continuation of this community." Every year, the active members are reduced in numbers and they do not have any clues on why a lot 
of them stop caring anymore about it.

In sociology, the undeveloped function of Buton youth community can be understood as it is encountering a social disorganization or social disintegration. It means the changing and dynamics in the community were caused by two main factors: the gap between the seniors and juniors, the juniors failed to take their senior's advice based on their experiences living in Gorontalo, and on the contrary the seniors cannot understand the mindset of the juniors in pursuing their goals as university students. This gap has been causing the collapse of close relations between the members. The relations become fragmented and resulting in many members losing their hope or getting frustrated for being unable to depend on community for fulfilling their basic and personal needs (Kartono 2014, p.5). Charles $\mathrm{H}$. Cooley stated the signal that institution also includes control-restrict mechanisms towards individual behavior. If the institution becomes inappropriate and less responsive toward the needs of the members, then it can reduce the authority of the institution and vitiate the control-restrict function. The process and condition of social disorganization is called formalism which has been producing many socio-pathological behaviors (ibid: 6).

Alienation is an indication that causes social disorganization, and Internet is an agent that may cause alienation of a person in his/her community. Internet has been blurring boundaries between human identities because the actual norms that come from information and communication technology imperatives has replaced the norms that arrange social relations based on status and role. In other words, now human relation systems are prefer to be relations based on task and purpose and this makes relations based on status and role become weak. Consequently, human relations are now more fragmented: general human identities such as ethnic, tradition, history, original region, religion and work place are still exist, but the radical development of information and communication technology has been conditioning human to minimize eve- ry relation with any communities based on the general human identities but maximize new relations with popular communities based on instantaneous hopes and needs.

Crow and Allan (1994) has explained that the notion of community in terms of shared locality or neighborhood is problematic already, and increasingly so in urban industrialized societies, characterized by high rates of mobility and complex social networks. The notion of community in terms of 'common identity' is scarcely less problematic. 'Race', ethnicity, and sexual orientation have each been considered, for example, as markers of 'communities of identity' (Mayo 200o, p.2). So problematic, it caused the writer (Mayo) to quote some important questions from other thinkers: from Weeks (1987) and Caplan (1987): how are these identities acquired, in any case, by nature and/ or by nurture? How do individuals and groups become conscious or fail to become conscious of themselves, in relation to these identities?(ibid). The problem of HIPPMIB is contained in the implementation of its motto: "Bolimo Karo Somanamo Lipu"or "prioritizing public interests rather than private ones." Prioritizing is interpreted by some active members as to provide more time by coming to community's gathering and religious events more often. What remains for HIPPMIB is the common interpretation that HIPPMIB is only an institution which has been ineffective in connecting most of the members for the continuation of the community.

The youth in HIPPMIB should improve their notion about the community. The meaning of 'Buton' as a part of the name of organization, has to be widened because it consists of two meanings: region and culture. Community was not simply locale; like the small-scale societies of the earliest ethnographies, it had become the nexus of an inextricable convergence between culture, place, intricate social relations and collective identity (Amit 2002, p.5). HIPPMIB members should be more conscious that their organization was not built to transfer the Buton people and culture to Gorontalo, but to become a media for every individual 
from Buton who wants to make new relationships and cooperation with people in Gorontalo. This means a member of HIPPMIB could unintentionally abandon community because perhaps he/she has been more capable in creating and maintaining important relationship for the progression of his/her existence in Gorontalo and he/ she chooses to prioritize his/her relations and activities in new communities more than in HIPPMIB.

\section{Sociological Approach for Buton Youth Community to Change}

The stagnancy of HIPPMIB has two main points: first, the community is being weakened in terms of the function to control; and second, the community is unsure about how to end the passiveness of its member. In order to settle this problem, it has to reflect upon the first initiative when it was found. Karl Marx, in Selected Works (1968) concerned both with the role of culture and ideas, and with human actors and the ways in which they construct meaning, and strategies for action. As Marx himself put this, in another much-quoted passage, men (and women) do make their own history. Although he went on to qualify this statement by pointing to the structural constraints on making history, arguing 'they do not make it just as they please: they do not make it under circumstances chosen by themselves, but under circumstances directly encountered, given and transmitted from the past' (Mayo 2000 p.22). Moreover, Bourdieu has seen human agency in collective as well as individual terms. Bourdieu's work addresses the problem of understanding how culture (defined both as 'high culture/art' and as 'ways of life') relates to political economy, taking account of structural factors without eliminating the role of human agents, reflecting upon their actions as they shape their social worlds (ibid, p.33-34).

Reflection through the initiative of early formation of HIPPMIB should not be construed as mere nostalgia activity. The purpose of reflection is to reaffirm the spirit on building a community. The main point of reflection is to discuss diverse challenges from inside and outside community which have shaped the problem in it all this time. Through the reflection, the community will collect aspirations from all members that are useful to improve its role to help reach their members'achievement.

Their experience in Internet use to support promotion of their members' innovation, product, and creativity is one important point to be reflected and discussed. Since HIPPMIB is defined as the gate for people from Buton who wants to make new life and involve with people in Gorontalo, Internet would be the best instrument to connect and relate HIPPMIB and its members to outside people with various identities in Gorontalo to establish a complex relationship and an economic cooperation. Reflection through the Internet use is not only to overcome technical problems such as the insufficiency of resources, infrastructures and support facilities, but also to design and organize the agenda of the Internet use in community. Many people are still unaware that one ultimate and never ending reason to establish a community or organization is to have strategies for empowerment and development, but now these has been presumed and oversimplified that if one can adapt and capable to use the latest technology then he/she may empower himself/herself and easily to cooperate with other people in the world.

Not every person in society has the ability to master the knowledge in technology. What is best for society is to teach them how to empower themselves as a community, and how they can achieve them and maintain what has been reached. The empowerment strategies for community members have been the prime issue in the 1980 s. Guy Gran (an American social scientist and development consultant) introduced the concept called "Development by the People" and emphasized the strategy to empower the poor and deprived social groups. This strategy has three elements, but the most suited elements for HIPPMIB to have the ability to empower its members are the first and third elements. First element is the process of awareness (conscientisation): a process through which people - not a pas- 
sive recipients but as knowingand active citizens - achieve a deeper understanding of the social reality which shapes their lives and their capacity to transform that reality (Martinussen 1997, p.335-336). This element is parallel with reflection process that is discussed above. Third element is to reorganize the local communities in such a way that citizens gain equal access to opportunities to influence decisions affecting their condition of life by reorganizing the local communities into relatively small units. This element stresses the importance of prioritizing many different issues and areas and only this way can they reach balanced decision on how to make the best use of the scarce resources available to satisfy the many different basic human needs (ibid). Empowering in the sense of reorganizing HIPPMIB means to make new priorities of objectives and goals after the process of reflection has been accomplished. This includes making standard of procedures in using Internet as a scarce resources of community in order to satisfy its members.

HIPPMIB and other similar communities need to learn from the experience of others that have conducted the process of reflection and reorganization and passed the period of stagnation. For example,a community named Associazione Quartieri Spagnoli (AQS) in Naples, Italy, has contributed significantly to the improvement of living standard and in bringing about changes in attitude, mentality and culture for the residents who were involved in the association's projects: they have not only attended training courses, found jobs and managed to satisfy other, previously unmet, needs, but have also become protagonists of change and no longer consider themselves as passive and disheartened onlookers (Cavola et al 2010, p.94). AQS has developed successfully after reorganization and formulated two community initiatives range namely community-centered initiatives and initiatives that have broad impact on society. If HIPPMIB can implement the substantially similar process of reorganization and initiatives then the Internet facility will increasingly be directed to be used positively, such as: to have an opportunity to get vast information, boosting social capital formation, facilitating participation for improving public education, helping organizations to be flexible in networking process, and to create a bountiful of culture diversity (DiMaggio et al 2001).

\section{CONCLUSION}

HIPPMIB not yet owns a developed view about its function and position in the current era of advanced information. The cause is that HIPPMIB emphasizes too significantly to the Buton's identity as regional rather than as cultural. The members realize that they are currently in Gorontalo and wish to find useful experience of social relationship through HIPPMIB, however it still faces many obstacles facilitating it. Of all the obstacles that present, Internet has become factors of alienation in community and causes of distancing relationship and social ties between the members. However, this community has tried to assist some creative and productive members with Internet and they appreciated it. Nevertheless, it is still not effective to overcome the passiveness and neglecting behavior of its members. Therefore, by investigating into sociological approach for community empowerment, HIPPMIB is suggested to change by taking two stages of actions: reflection and reorganization.

\section{REFERENCES}

Amit, V., 2002. Realizing Community: Concepts, Social Relationships and Sentiments. Routledge, London.

Arcidiacono, C., Procentese, F. and Di Napoli, I., 2007. Youth, community belonging, planning and power. Journal of Community $\mathcal{E}$ Applied Social Psychology, 17(4), pp.280-295.

Budiman, H., Munawar, S. \& Djohar, S.A., 2013. Berbagi Pengalaman: Pelatihan Penelitian Kualitatif untuk Pekerja Organisasi Masyarakat Sipil. The Interseksi Foundation, Jakarta.

Cavola, L., di Martino, P. \& de Muro, P. How to Make Neighbors Act? The Associazione Quartieri Spagnoli in Naples.in: Frank Moulaert, FlaviaMartinelli, Erik Swyngedouw\& Sara Gonzalez. 2010. Can Neighborhood Save the City? Community Development and Social Innovation. Routledge, New York.

Checkoway, B.N. and Gutierrez, L.M., 2006. Youth participation and community change: An introduction. Journal of Community Practice, 
14(1-2), pp.1-9.

Christensen, K \& Levinson, D. (ed.)., 2003. Encyclopedia of Community: From the Village to the Virtual World. SAGE, Thousand Oaks.

DiMaggio, P., Hargittai, E., W, R. N.,\& Robinson, J.P., 2001. Social Implications of The Internet. Annual Review of Sociology.27, pp.307-36. Retrieved from http://search.proquest.com/doc view/199578663?accountid=25704

Evans, S.D. and Prilleltensky, I., 2007. Youth and democracy: Participation for personal, relational, and collective well-being. Journal of community psychology, 35(6), pp.681-692.

Henslin, J.M., 2006. Sosiologi dengan Pendekatan Membumi. Erlangga, Jakarta.

Kartono, K., 2014. Patologi Sosial. Jilid 1.14 $4^{\text {th }}$ edition. Rajawali Pers, Jakarta.

Lerner, R.M., Lerner, J.V., Almerigi, J.B., Theokas, C., Phelps, E., Gestsdottir, S., Naudeau, S., Jelicic, H., Alberts, A., Ma, L. and Smith, L.M., 2005. Positive youth development, participation in community youth development programs, and community contributions of fifth-grade adolescents: Findings from the first wave of the 4-H study of positive youth development. The Journal of Early Adolescence, 25(1), pp.17-71.

Martinussen, J., 1997. Society, State and Market: A Guide to Competing Theories of Development. Zed Books, London \& New York.

Mayo, M., 200o. Cultures, Communities, Identities
Cultural Strategies for Participation and Empowerment. Palgrave, New York.

McDonald, K., 1999. Struggles for Subjectivity: Identity, Action and Yotuh Experience. Cambridge, New York.

Nygreen, K., Ah Kwon, S. and Sanchez, P., 20o6. Urban youth building community: Social change and participatory research in schools, homes, and community-based organizations. Journal of Community Practice, 14(1-2), pp.107-123.

Sexton, T. and Turner, C.W., 2010. The effectiveness of functional family therapy for youth with behavioral problems in a community practice setting. Journal of Family Psychology, 24(3), p.339.

Wang, C.C., 20o6. Youth participation in photovoice as a strategy for community change. Journal of community practice, 14(1-2), pp.147-161.

Watts, R.J. and Flanagan, C., 2007. Pushing the envelope on youth civic engagement: A developmental and liberation psychology perspective. Journal of community psychology, 35(6), pp.779-792.

Wheeler, W. and Edlebeck, C., 20o6. Leading, learning, and unleashing potential: Youth leadership and civic engagement. New Directions for Student Leadership, 2006(109), pp.89-97.

Wirth, L., 1930. Urbanism as a Way of Life.in: Jan Lin \& Christopher Mele. 2005. The Urban Sociology Reader. Routledge, London. 